Article

\title{
Dynamic Mechanical Properties of Slag Mortar with Alkali-Resistant Glass Fiber
}

\author{
Haibin Ma *, Shaofan Yang, Ying Xu, Peiyuan Chen and Liang Wang
}

check for updates

Citation: Ma, H.; Yang, S.; Xu, Y.; Chen, P.; Wang, L. Dynamic Mechanical Properties of Slag Mortar with Alkali-Resistant Glass Fiber. Buildings 2022, 12, 266. https:// doi.org/10.3390/buildings12030266

Academic Editors: Haoxin Li,

Cong Ma and Tao Shi

Received: 7 January 2022

Accepted: 17 February 2022

Published: 24 February 2022

Publisher's Note: MDPI stays neutral with regard to jurisdictional claims in published maps and institutional affiliations.

Copyright: (C) 2022 by the authors. Licensee MDPI, Basel, Switzerland. This article is an open access article distributed under the terms and conditions of the Creative Commons Attribution (CC BY) license (https:// creativecommons.org/licenses/by/ $4.0 /)$.
School of Civil Engineering and Architecture, Anhui University of Science and Technology, Huainan 232001, China; chqyao@aust.edu.cn (S.Y.); yxu@aust.edu.cn (Y.X.); pychen@aust.edu.cn (P.C.); 2018028@aust.edu.cn (L.W.)

* Correspondence: hbma@aust.edu.cn

\begin{abstract}
To investigate the influence of alkali-resistant glass fiber on the dynamic mechanical properties and microstructure of slag cement mortar (SCM), five SCM blocks with different volumes of alkali-resistant glass fiber $(0 \%, 0.25 \%, 0.5 \%, 0.75 \%$, and $1 \%)$ were prepared. A split Hopkinson pressure bar (SHPB) test device with a diameter of $\Phi 50 \mathrm{~mm}$ was used to test the impact compression under different loading pressures. In this way, the stress-strain curve of SCM under average strain rates corresponding to different loading air pressures is obtained, and the relationship between the ultimate toughness, the dynamic increase factor (DIF), and the fiber content of SCM can be comprehensively analyzed in combination with the dynamic and static mechanical parameters. Research results showed that, with the increase in fiber content, the static compressive strength of the SCM showed a trend of first increasing and then decreasing, where $0.75 \%$ can be the optimal one with the maximum compressive strength. Under the impact load, the dynamic compressive strength of the SCM had a positive correlation with the average strain rate. Within the strain rate range of $75.03 \mathrm{~s}^{-1} \sim 141.47 \mathrm{~s}^{-1}$, When the fiber volume content is $0.75 \%$, the dynamic compressive strength, ultimate toughness and DIF of SCM are higher than those of other groups, showing good impact resistance. According to the analysis of SEM images, the bonding performance between alkali-resistant glass fiber and cement matrix was strong, and the fibers were interlaced in the mortar to form a network structure, which has a good effect on toughening and strengthening the SCM.
\end{abstract}

Keywords: alkali-resistant glass fiber; SCM; split Hopkinson pressure bar (SHPB); dynamic mechanical properties; microstructure

\section{Introduction}

Nowadays, slag cement has wide applications as a kind of binary cement, with features like low cost, good impermeability, and corrosion resistance [1]. It is much greener than pure cement, since partial cement is substituted by slag, which is a byproduct of pig iron, with less $\mathrm{CO}_{2}$ being released into the air. However, studies show that concrete made by slag cement is vulnerable to brittle damage when it suffers an impact load [2]. Slag cement concrete displays inferior impact resistance to cement concrete [3]. Consequently, it is particularly important to improve the impact resistance of slag concrete. Related studies show that adding fibers to the concrete matrix, to some extent, can make up for some of the defects in concrete [4], improve the strength and durability of concrete, and reduce the brittle damage of concrete under the impact load. Therefore, fiber finds promising application in enhancing the performance of cement matrix materials $[5,6]$.

Blast slag, as a waste residue discharged from the blast furnace during smelting iron, is usually used in concrete as a mineral admixture, because of its potential hydraulic activity [7]. The durability of concrete, such as anti-permeability and corrosion resistance, can be improved by adding blast slag during concrete mixing. The concrete with blast slag is suitable for road, dock, tunnel engineering [8]. Although a concrete made with slag can 
enhance mechanical strength at a later age, it is prone to brittle damage under impact loads, which exposes the inherent defects in the matrix [2]. The impact resistance of concrete with slag was reduced compared with the one without slag [3]. In some load cases, the concrete with slag makes it easier to produce creaks than ordinary concrete [8].

To overcome the drawback of concrete with slag, glass fiber was used in slag concrete to enhance the impact resistance [9]. Alkali-resistant glass fiber, as a material with high monofilament tensile strength, high elastic modulus, alkali resistance, corrosion resistance, and impact resistance, has a wide range of applications in the field of construction engineering, mainly used in non-load-bearing cement components [10]. It can be used as an auxiliary rib material to enhance the performance of concrete, and an appropriate amount of it can effectively improve the toughness of cement matrix [11]. The study by Yue et al. $[10,12,13]$ showed that blast furnace slag can be used as a raw material to prepare alkali-resistant glass fibers, and they found that it was a method to recycle waste materials, which improved the value of both, while protecting the environment. Related research had pointed out that, under impact loading, the number of surface cracks and crack width of concrete slabs mixed with alkali-resistant glass fiber was reduced [9]. Yue et al. [10,14] found that different amounts of alkali-resistant glass fiber can effectively improve the impact resistance of the cement substrate system. Deng et al. [15] found that alkali-resistant glass fiber can effectively improve the impact toughness of concrete slabs, and with the increase in fiber content, the impact-resistant performance effect is more obvious.

On the basis of the above-mentioned research, in the view of the defects of poor impact resistance of SCM, static compression strength test, microstructure analysis, and impact compression, a test was carried out on five kinds of SCM, with different amounts of alkali-resistant glass fiber, and the relationship between stress, toughness, DIF, and the strain rate under dynamic loading test was analyzed according to static loading law. The groups of adding fibers had superior performance in dynamic compressive strength and ultimate toughness; the incorporation of alkali-resistant glass fiber into SCM promoted the impact resistance of SCM. The addition of alkali glass fiber improves the impact resistance of SCM and makes up for the inherent defect that the matrix is prone to brittle damage under impact load. Moreover, the bonding performance between alkali-resistant glass fiber and cement matrix was strong, and the fibers were interlaced in the mortar to form a network structure, which had a good effect on toughening and strengthening the SCM, providing a reference for a practical application of engineering.

\section{Experiments and Methods}

\subsection{Materials}

The cement used in this study is Conch branded P. O. 42.5. Slag is granulated blast furnace slag with an average particle size of $17.8 \mu \mathrm{m}$. Sand was natural river sand with a fineness of modulus of 2.56. Water was ordinary tap water. The length of the used alkali-resistant glass fiber was $12 \pm 2 \mathrm{~mm}$, and its physical properties were presented in Table 1. The photos of materials, samples and experiments are shown in Figure 1.

Table 1. Physical and mechanical properties of alkali-resistant glass fiber.

\begin{tabular}{|c|c|c|c|c|}
\hline Length/mm & Diameter/ $\mu \mathrm{m}$ & Density $/\left(\mathrm{g} / \mathrm{cm}^{3}\right)$ & $\begin{array}{c}\text { Modulus of } \\
\text { Elasticity/GPa }\end{array}$ & $\begin{array}{c}\text { Tensile } \\
\text { Strength/MPa }\end{array}$ \\
\hline $12 \pm 2$ & 14 & 2.68 & 72 & 1800 \\
\hline
\end{tabular}




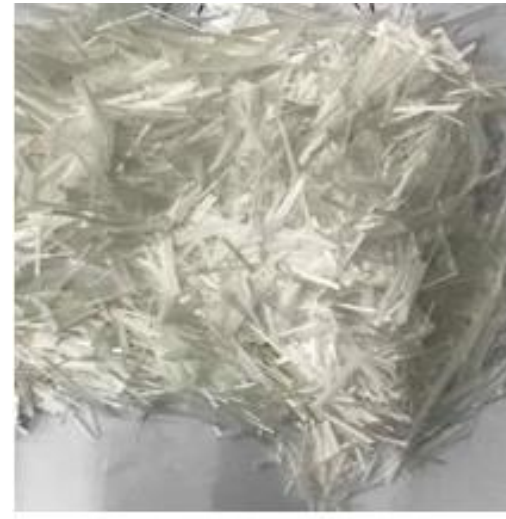

(a. ) Alkali-Resistant Glass Fiber

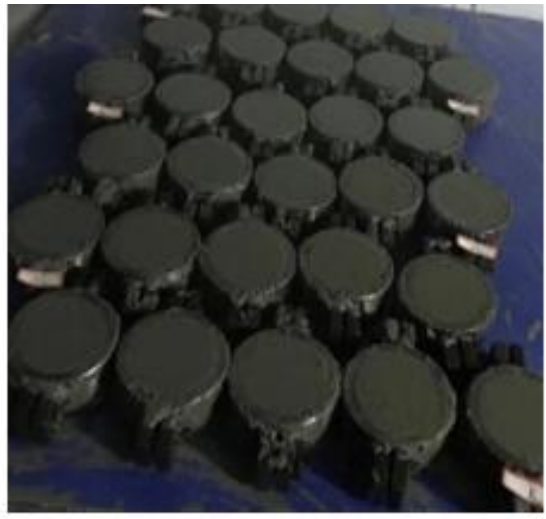

(b) Test block

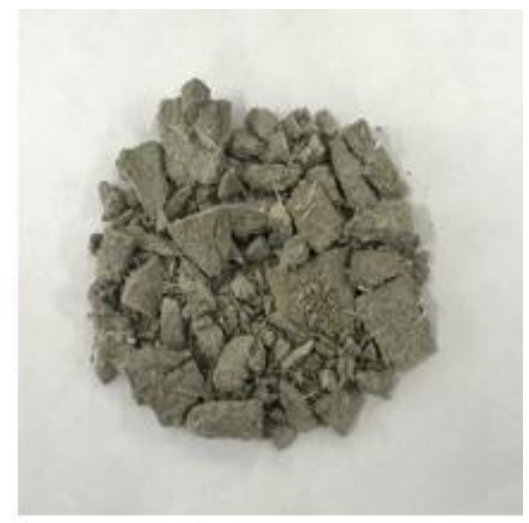

(c) Sample after test

Figure 1. Photos of the materials, samples and experiments.

\subsection{Mix Proportion and Sample Preparation}

Slag was used as the supplementary cementitious material to replace $20 \%$ cement by mass. Mortar samples with a water-binder ratio of 0.4 were prepared to examine the effects of FP on the static and dynamic mechanical properties of slag cement-based materials. The content of alkali-resistant glass fiber by volume of mortar samples was $0 \%$ (Control), $0.25 \%$, $0.5 \%, 0.75 \%$, and $1 \%$, respectively, which correspond to mixtures of G0, G0.25, G0.5, G0.75, and G1, as shown in Table 2.

Table 2. Mixing proportion.

\begin{tabular}{cccccc}
\hline \multirow{2}{*}{ Mixtures } & \multirow{2}{*}{ Fiber Content by Volume/\% } & \multicolumn{4}{c}{ Material $\mathbf{( k g / \mathbf { m } ^ { \mathbf { 3 } } )}$} \\
\cline { 3 - 6 } & & Cement & Water & Sand & Slag \\
\hline G0 & 0 & 291.6 & 145.8 & 510.3 & 72.9 \\
G0.25 & 0.25 & 291.6 & 145.8 & 510.3 & 72.9 \\
G0.5 & 0.5 & 291.6 & 145.8 & 510.3 & 72.9 \\
G0.75 & 0.75 & 291.6 & 145.8 & 510.3 & 72.9 \\
G1 & 1 & 291.6 & 145.8 & 510.3 & 72.9 \\
\hline
\end{tabular}

The compressive strength of SCM was tested on $50 \mathrm{~mm} \times 50 \mathrm{~mm} \times 50 \mathrm{~mm}$ cubic samples. They were cured as standard in a curing room with a temperature of $20 \pm 3$, $\mathrm{RH}>95 \%$. The research from Chen et al. [16] showed that, when the length-to-diameter ratio of the test block is 0.5 , the impact of inertia effect and friction effect can be reduced. Round cake samples with diameter of $50 \mathrm{~mm}$ and height of $25 \mathrm{~mm}$ were prepared to test the dynamic mechanical properties of SCM with different fiber content. In order to make the fiber evenly distributed in the slurry, the preparation process of the test block was as follows: firstly, cement, slag, and sand were added into the mixer and stirred for $2 \mathrm{~min}$, then added water and stirred for 2 min until the slurry was viscous, and finally, sprinkled the fibers into the mixer, stirred for 1 to 2 min and cast block.

\subsection{Experimental Equipment and Methods}

(1) Static test. According to the specifications of ASTM-C109 [17], the static compression strength of the SCM was tested by a digital pressure testing machine, with 3 samples as a group, and the test results were averaged.

(2) Dynamic test. A split Hopkinson pressure bar (SHPB) system with $\Phi 50 \mathrm{~mm}$ was used to perform a uniaxial impact compression test on the samples. The test device is shown in Figure 2. The elastic modulus of the bar is $210 \mathrm{GPa}$, the density is $7800 \mathrm{~kg} / \mathrm{m}^{3}$, and the longitudinal wave velocity is $5190 \mathrm{~m} / \mathrm{s}$. 


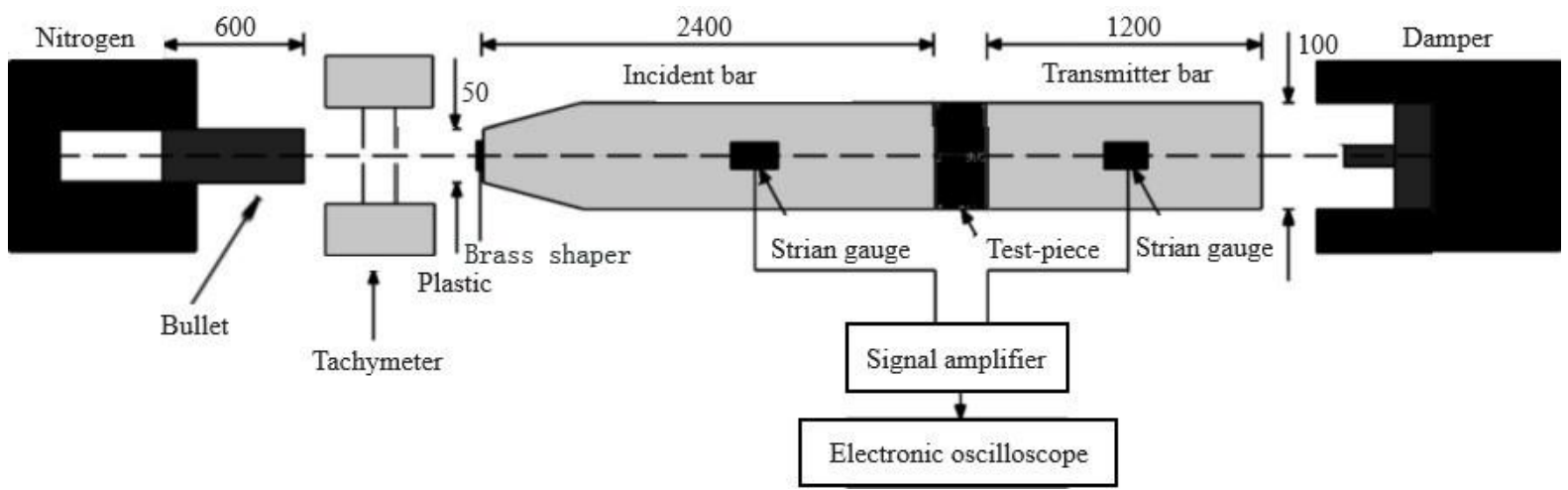

Figure 2. SHPB device.

The "three-wave method" was used to calculate the axial stress, strain rate, and strain of the samples [18], the formulae are as follows:

$$
\begin{gathered}
\sigma(t)=\frac{S_{B} E}{2 S_{a}}\left[\varepsilon_{i}(t)+\varepsilon_{r}(t)+\varepsilon_{t}(t)\right] \\
\varepsilon(t)=\frac{C_{0}}{L_{a}} \int_{0}^{t}\left[\varepsilon_{i}(t)-\varepsilon_{r}(t)-\varepsilon_{t}(t)\right] \\
\dot{\varepsilon}(t)=\frac{C_{0}}{L_{a}}\left[\varepsilon_{i}(t)-\varepsilon_{r}(t)-\varepsilon_{t}(t)\right]
\end{gathered}
$$

where, $\sigma(t)$ is the stress, $\varepsilon(t)$ is the strain, $\dot{\varepsilon}(t)$ is strain rate; $S_{B}$ is cross-sectional area of $\operatorname{rod}, E$ is the modulus of elasticity of concrete in MPa; $S_{a}$ is cross-sectional area of block, $L_{a}$ is initial length; $C_{0}$ is wave velocity of bar; $\varepsilon_{i}(t), \varepsilon_{r}(t)$ and $\varepsilon_{t}(t)$ are the strain pulses corresponding to the incident wave, reflected wave, and transmitted wave.

In this study, dynamic compression tests were carried out under three different launch air pressures of $0.3,0.4$, and $0.5 \mathrm{MPa}$, respectively, and the impact tests were performed three times for each samples group under the same air pressure. Before tests, the bars of SHPB were leveled to keep each bar on the same horizontal axis, and then a brass wave shaper was attached to the end of the incident bar, and a small amount of petroleum jelly was applied to both ends of the samples.

\section{Results and Discussions}

\subsection{The Relationship between Fiber Content and Static Compressive Strength of SCM}

Figure 3 shows the changing trend of the static compressive strength of five groups of SCM with different alkali-resistant glass fiber content. It can be seen that the static compressive strength increased firstly, and then decreased as the content of alkali-resistant glass fiber increased. When it came to the highest strength, the fiber content was $0.75 \%$. By comparing the strength of different ages, it can be found that the strength of the $28 \mathrm{~d}$ samples increased more than that of the $7 \mathrm{~d}$. 


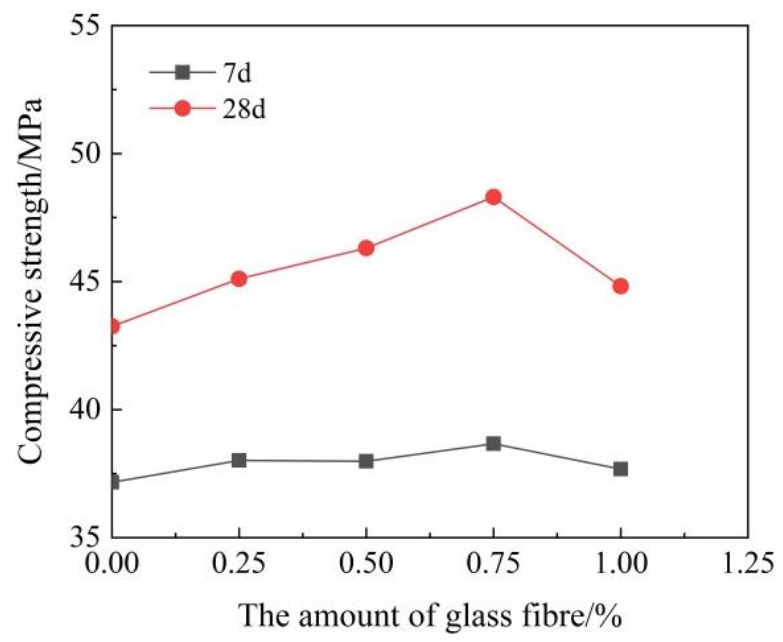

Figure 3. Relationship between the amount of alkali-resistant glass fiber and the static compressive strength of SCM.

The main reasons for the above results are as follows: (1) The incorporation of fiber into the concrete system breaks the inherent system of the original ecological concrete. For example, in terms of compressive strength, the amount of fiber is in the range of $0 \sim 1 \mathrm{~kg} / \mathrm{m}^{3}$, which will change the internal structure of the concrete body. The increase in fiber content will increase the number of interfaces between the concrete body and the cement matrix, increase the weak links inside the body, and reduce the compressive strength of the concrete; (2) When the fiber content is in the range of $1 \sim 1.5 \mathrm{~kg} / \mathrm{m}^{3}$, the fiber can enhance the bonding performance between the fiber and the interior of the concrete, and have a good restraint effect on the transverse expansion deformation of the concrete under pressure. This restraint effect is greater than the negative effect brought by the fiber, so that the $7 \mathrm{~d}$ and $28 \mathrm{~d}$ compressive strength of the concrete has been improved to a certain extent; (3) When the fiber content has reached a certain value, fibers will cause changes in the internal structure of the SCM. Under this condition, the interfaces between the fibers and the cement matrix have a number-adding change, which leads to an increase in the weak links of the aggregate [15]. With the continuous increase in fiber content, agglomeration and unevenness will occur between fibers, which is easy to reduce the workability of concrete. Moreover, the increase in fiber content increases the specific surface area of fibers. Too many fibers increase the weak interface between fibers and the concrete matrix. When the weak interface effect is better than the reinforcement effect of fibers, it shows the decrease in concrete strength [19].

\subsection{The Influence of Fiber Incorporation on the Dynamic Stress-Strain Curve of SCM}

The pulse waveform data were generated by the incident rod and the transmission rod strain gauge in this experiment. After the processing of the above formulas, the statistics of stress and strain can be obtained, and accordingly, the stress-strain curve of the mortar samples under the impact load is drawn in Figures 4 and 5. In this experiment, the impact air pressures are $0.3 \mathrm{MPa}, 0.4 \mathrm{MPa}$, and $0.5 \mathrm{MPa}$ respectively, which correspond to three average strain rate loading ranges of 75.03 94.01 s $\mathrm{s}^{-1}, 100.27 \sim 111.68 \mathrm{~s}^{-1}$ and $134.11 \sim 141.47 \mathrm{~s}^{-1}$, respectively. 


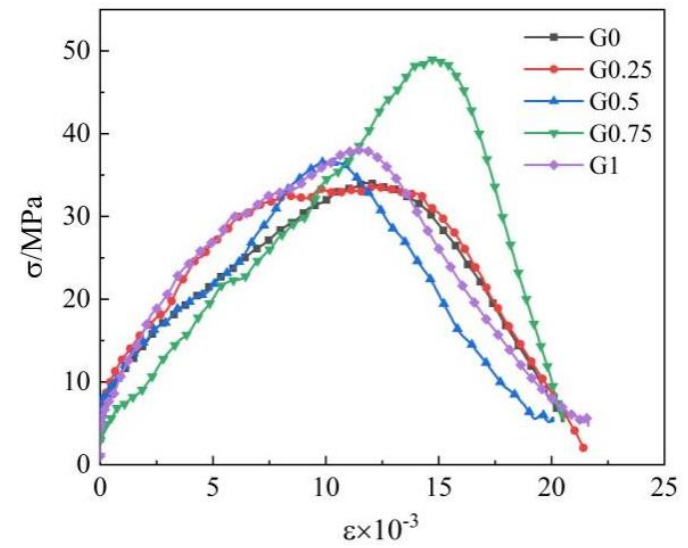

(a)

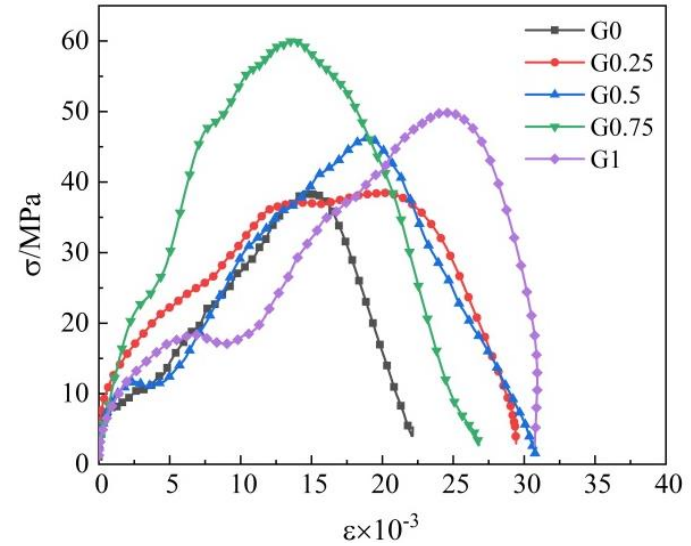

(b)

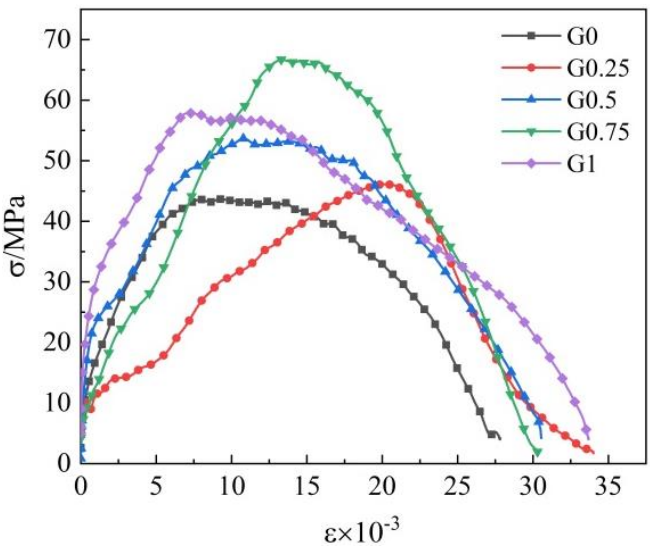

(c)

Figure 4. Mortar stress-strain curve under three loading ranges of average strain rate: (a) $75.03 \sim 94.01 \mathrm{~s}^{-1}$; (b) $100.27 \sim 111.68 \mathrm{~s}^{-1}$; (c) $134.11 \sim 141.47 \mathrm{~s}^{-1}$.

It can be seen from Figure 4 that the stress-strain curve of the SCM samples can be divided into four stages; namely, the compaction stage, the elastic stage, the elastoplastic stage, and the plastic failure stage. In the compaction stage, which processes all five types of mortar samples, the curve is concave. As the contact surfaces between the incident rod and the test block were gradually compacted by the stress, the anti-deformation ability of samples was continuously increasing with internal defects, and voids were gradually reduced [20]. When it comes to the elastic stage, the axial stress-strain curve shows a linear growth trend, and the elastic modulus gradually increases before reaching a certain value. What's more, it can be seen that the four-fiber content has different effects on peak stress's increase. As the stress keeps increasing, the curve is characterized by an upward convex shape when it comes to the elastoplastic stage, and the growth of the axial stress-strain curve slows down. At this stage, the internal cracks of the test block gradually become more significant [21]. In the failure stage, the stress dropped rapidly with the increase in strain after the stress reached the peak value. Under this condition, the samples gradually reached the limit strength and then were destroyed. A segment of the curve shows "phenomenon of stress drop" in the initial stage, which is equal to a short decrease and then an increase in stress. This phenomenon is caused by the rough surface of the samples. After the incident rod hitting the surface, the stress began to increase. Along with this, the samples were kept being on loading until they got crushed when the load exceeded its strength limit. Then, the curve demonstrated the phenomenon transiently with the drop of stress, and the stress began to rise when the contact surface of the incident rod and the test block completely overlapped.

Different performances of five groups of samples can be shown in the figure. When its stress reached its peak value, there was a typical brittle failure occurring in G0, which 
was characterized by being crushed down and losing bearing capacity; after getting to the peak stress, the G0.25 showed good deformation performance compared with the other three fiber content groups. Their stress could keep a certain numerical value for a while, and then started to drop under the condition that the strain increased. There was a random failure that occurred in G0.75 after reaching its peak stress, whose numerical value was bigger than others. Moreover, the deformation capacity of G0.75 was not as good as that of G0.25, but better than that of G0, G0.5, and G1.

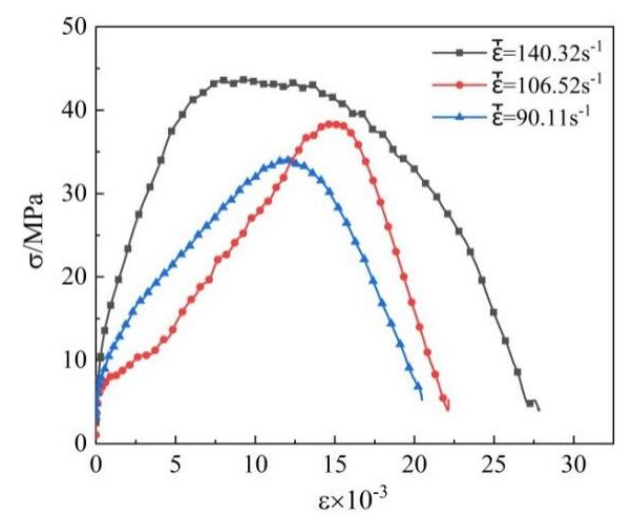

(a)

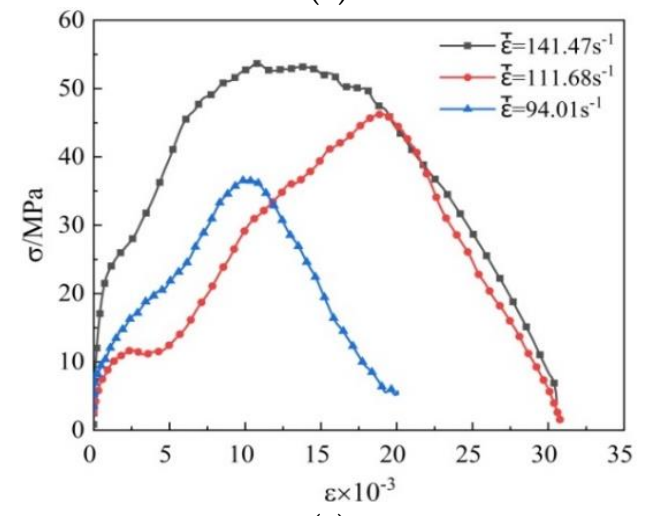

(c)

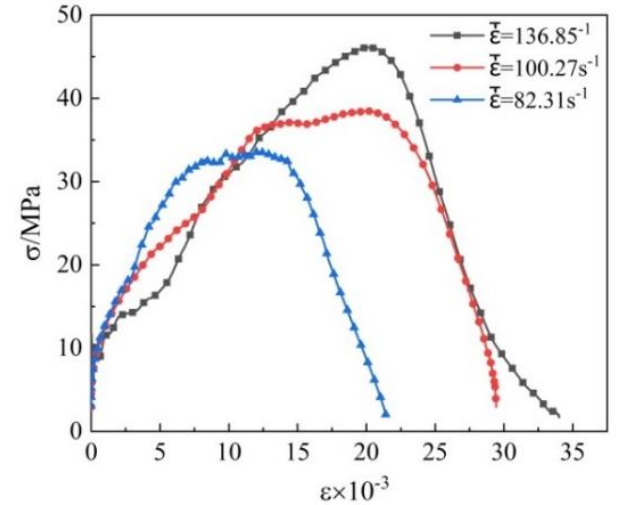

(b)

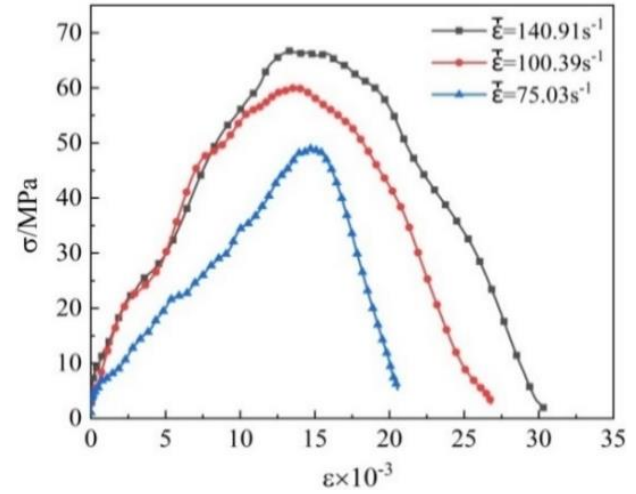

(d)

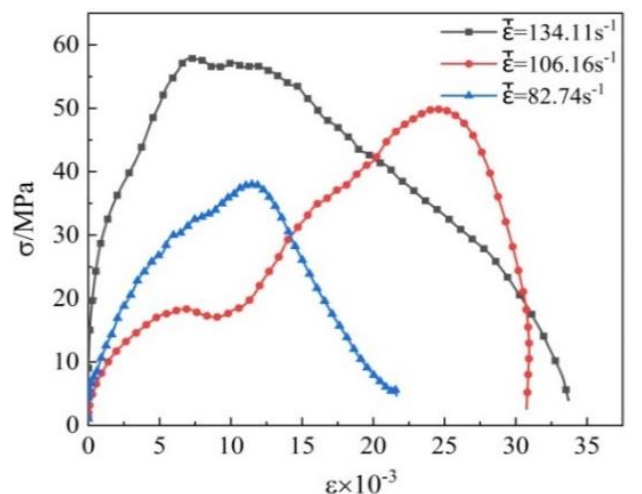

(e)

Figure 5. Stress-strain curve of SCM with five fiber contents: (a) G0; (b) G0.25; (c) G0.5; (d) G0.75; (e) G1.

As is shown in Figure 5 five group curves all show different characteristics. For example, the G0.75 (Figure 5d) represents a typical triangular shape, which can demonstrate that the peak stress has a more significant performance under different average strain rate levels; in Figure 5b, a short platform segment appears at the peak stress of the G0.25 group, indicating that the strength keeps basically steady within a certain strain rate range, which 
is consistent with the characteristics of the SCM stress-strain curve of $0.25 \%$ fiber doped under different average strain rate loading range. Furthermore, with an increase in the average strain rate, it can be found in Figure 5 that the peak stress and ultimate strain have a positive correlation.

This is because, on one hand, the loading rate for samples was slow under low strain rate loading; meanwhile, the loading time can keep consistent with the speed of internal stress balance and micro-cracks development [22]; on the other hand, the energy provided by the external impact device was larger under high strain rate loading; therefore, the energy absorbed by the test block had an increase, resulting in the promotion in the initial crack strength. When the samples were loaded to their peak stress, and the energy absorbed by the fiber to restrain the internal cracks was insufficient to offset the external impact energy, the samples were going to crack and break.

A large number of studies show that there is a great relationship between material strength and load form. The strength of structural members bearing explosion load is higher than that of the same members bearing static load. The general view is that the increase in the strength of concrete and reinforcement materials is due to the high strain rate occurring in members subjected to dynamic load. Under high strain rate, concrete and reinforcement show greater strength, and the higher the strain rate, the higher the compressive strength of concrete, and the higher the yield strength and ultimate strength of reinforcement [23]. This phenomenon of strength improvement has been widely verified, and has been applied to the design of practical projects. Relevant research shows the approximate range of material strain rate response under different load forms: the material strain rate under quasi-static load is about $10^{-6} \sim 10^{-5} \mathrm{~s}^{-1}$, the material strain rate under seismic load is about $10^{-3} \sim 10^{-1} \mathrm{~s}^{-1}$, the material strain rate under impact load is about $10^{0} \sim 10^{2} \mathrm{~s}^{-1}$, and the material strain rate under explosion load can reach $10^{3} \sim 10^{4} \mathrm{~s}^{-1}$. The strain rate of materials under different forms of loads varies greatly [23]. The strain rate under impact and explosion loads is significantly greater than that under static and quasistatic loads. The mechanical properties of materials will also be significantly different from those under static and quasi-static loads.

\subsection{Effect of Fiber Content on Dynamic Mechanical Properties of SCM}

In order to further explore the influence of alkali-resistant glass fiber on the dynamic mechanical properties of SCM, the test parameters in Figures 3-5 are integrated, as shown in Table 3.

Table 3. Performance parameters of mortar.

\begin{tabular}{|c|c|c|c|c|c|c|c|c|}
\hline $\begin{array}{c}\text { Mix } \\
\text { Number }\end{array}$ & Code & $\begin{array}{c}\text { Statistic } \\
\text { Compressive } \\
\text { Strength/MPa }\end{array}$ & $\begin{array}{l}\text { Average Strain } \\
\text { Rate } / \mathbf{s}^{-1}\end{array}$ & $\begin{array}{c}\text { Peak } \\
\text { Stress/MPa }\end{array}$ & DIF & $\begin{array}{c}\text { Ultimate } \\
\text { Toughness } /\left(\mathrm{J} \cdot \mathrm{cm}^{-3}\right)\end{array}$ & $\begin{array}{l}\text { Ultimate } \\
\text { Strain }\end{array}$ & $\begin{array}{l}\text { Impact Air } \\
\text { Pressure/MPa }\end{array}$ \\
\hline \multirow{3}{*}{ G0 } & G0-1 & \multirow{3}{*}{43.350} & 90.11 & 34.050 & 0.785 & 0.4743 & 0.0205 & 0.3 \\
\hline & G0-2 & & 106.52 & 38.326 & 0.884 & 0.4933 & 0.0221 & 0.4 \\
\hline & G0-3 & & 140.32 & 43.649 & 1.007 & 0.8932 & 0.0278 & 0.5 \\
\hline \multirow{3}{*}{ G0.25 } & G0.25-1 & \multirow{3}{*}{45.019} & 82.31 & 33.838 & 0.752 & 0.5150 & 0.0214 & 0.3 \\
\hline & G0.25-2 & & 100.27 & 38.460 & 0.854 & 0.8347 & 0.0294 & 0.4 \\
\hline & G0.25-2 & & 136.85 & 46.112 & 1.024 & 0.9035 & 0.0340 & 0.5 \\
\hline \multirow{3}{*}{ G0.5 } & G0.5-1 & \multirow{3}{*}{46.206} & 94.01 & 36.593 & 0.792 & 0.4351 & 0.0201 & 0.3 \\
\hline & G0.5-2 & & 111.68 & 46.243 & 1.001 & 0.8004 & 0.0305 & 0.4 \\
\hline & G0.5-3 & & 141.47 & 53.672 & 1.162 & 1.1748 & 0.0308 & 0.5 \\
\hline \multirow{3}{*}{ G0.75 } & G0.75-1 & \multirow{3}{*}{48.176} & 75.03 & 48.973 & 1.016 & 0.5682 & 0.0205 & 0.3 \\
\hline & G0.75-2 & & 100.39 & 59.965 & 1.245 & 1.0062 & 0.0268 & 0.4 \\
\hline & G0.75-3 & & 140.91 & 66.699 & 1.384 & 1.2660 & 0.0303 & 0.5 \\
\hline \multirow{3}{*}{ G1 } & G1-1 & \multirow{3}{*}{44.819} & 82.74 & 38.062 & 0.849 & 0.5149 & 0.0216 & 0.3 \\
\hline & G1-2 & & 106.16 & 49.843 & 1.112 & 0.9180 & 0.0308 & 0.4 \\
\hline & G1-3 & & 134.11 & 57.860 & 1.291 & 1.2393 & 0.0337 & 0.5 \\
\hline
\end{tabular}


According to the statistics in Table 3, the dynamic compressive strength $f_{c}$ and the average strain rate $\overline{\dot{\varepsilon}}$ of the mortar under different fiber content were fitted (Figure 6), and the relationship is shown below:

$$
\left\{\begin{array}{c}
f_{c-G 0}=17.20094+0.19249 \overline{\dot{\varepsilon}} \\
f_{c-G 0.25}=15.43879+0.22572 \overline{\dot{\varepsilon}} \\
f_{c-G 0.5}=5.196730+0.34831 \overline{\dot{\varepsilon}} \\
f_{c-G 0.75}=31.18034+0.25953 \overline{\dot{\varepsilon}} \\
f_{c-G 1}=-5.87999+0.52848 \overline{\dot{\varepsilon}}
\end{array}\right.
$$

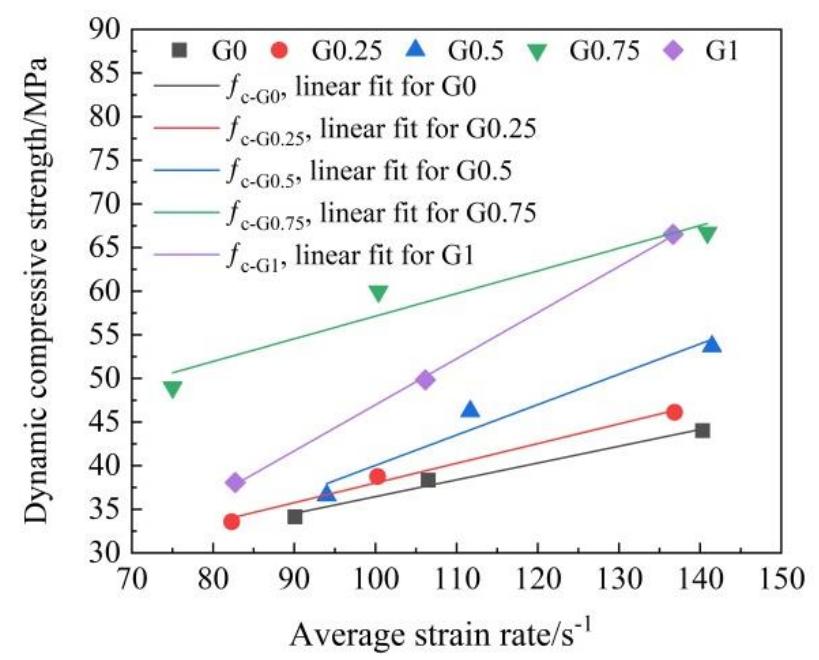

Figure 6. Relationship between dynamic compressive strength and average strain rate of alkali-resistant glass fiber slag mortar.

It can be seen in Figure 6 that, in the strain rate range $75.03 \sim 141.47 \mathrm{~s}^{-1}$, the dynamic compressive strength of SCM and the average strain rate have a positive correlation. Moreover, the fitting curves of dynamic compressive strength of the G0 group are below the other four groups, which indicated that the addition of alkali-resistant glass fiber has a better effect on the improvement of the dynamic compressive strength of SCM. Furthermore, regardless of the lower or higher average strain rate of loading, the dynamic compressive strength of G0.75 maintained its maximum value. This can be attributed to the promotion of two-dimensional and three-dimensional fiber network structures in the internal structure of the mortar, which have a better restraint effect on the lateral expansion and deformation when the mortar was under shock compression. In addition, there is a certain distance between the fibers, which effectively inhibited the development of cracks in the matrix, and increased the overall energy absorption effect of the mortar [24], making the mortar show good deformability under impact loading. However, the impact resistance of the mortar got worse when the fiber content was too much, as a result of fiber agglomeration and small fiber spacing. Therefore, the effect of the mortar against impact loading achieved the best result when the alkali-resistant glass fiber content was $0.75 \%$.

The ultimate toughness of mortar refers to the envelope area of the dynamic stressstrain curve [25], which can reflect the amount of energy absorbed during the deformation of the mortar under impact loading, and comprehensively manifest the properties of strength and ductility of the mortar [26]. As shown in Table 3, the ultimate toughness value of G0.75 increases from 0.5682 to 1.2660 in the strain rate range of $75.03 \mathrm{~s}^{-1} \sim 141.47 \mathrm{~s}^{-1}$, and the numerical value is higher than that of other groups under the same condition, which indicates that SCM, with $0.75 \%$ fiber content, has a stronger ability to resist impact load by absorbing more impact energy. 
DIF (i.e., the ratio of dynamic compressive strength to static strength) is set as the strength growth index to show the impact resistance of SCM with different amounts of alkali resistant glass fiber. It can be seen from Table 3 that, under the same strain rate, the DIF of G0.75 mortar is higher than that of the control group, and its ultimate toughness is also improved. Overall, the G0.75 groups have preferable impact resistance.

\subsection{Microstructure Analysis of Alkali-Resistant Glass Fiber SCM}

A SEM test was carried out on 28 d G0.75 samples to observe the bonding morphology and structural characteristics of aggregates and fibers visually in the mortar under impact loading. As shown in Figure 7a, b, the alkali-resistant glass fiber is wrapped by the cement matrix, which leads to a better cementation for them. Moreover, the partial hydration products attached to the fiber surface maintain a good connection between the fiber and the cement matrix, improving the toughness of the mortar. Relevant studies have shown that the strength of the bonding performance between the fiber and the cement matrix has a certain effect on the toughness of the cement matrix [19]. It can be seen from Figure 7c that the slippage that occurred between the fiber and the cement matrix by external force makes a good bridging effect of fiber and renders a good restraint for cracks. Besides, Figure $7 \mathrm{~d}$ shows that the distribution of fibers in the mortar was characterized by a network structure, with fibers interlacing, and overlapping each other. Consequently, fibers can effectively restrain the lateral expansion of the matrix by external force, which has a great improvement in the impact resistance of the mortar. Meanwhile, these studies also are consistent with the results of the influence of the incorporation of alkali-resistant glass fiber on the dynamic mechanical properties of SCM.

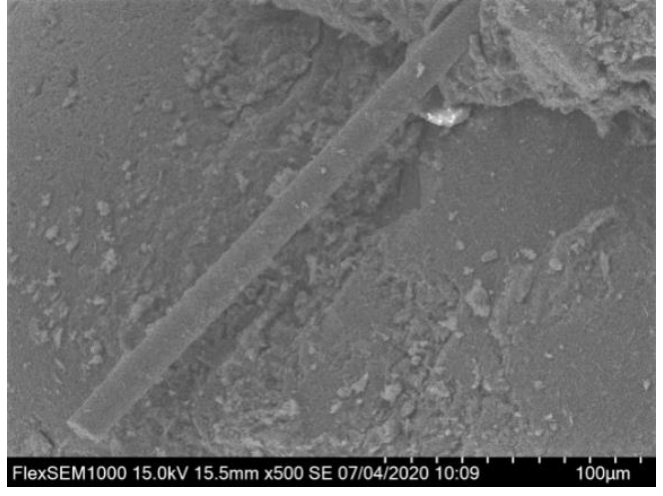

(a)

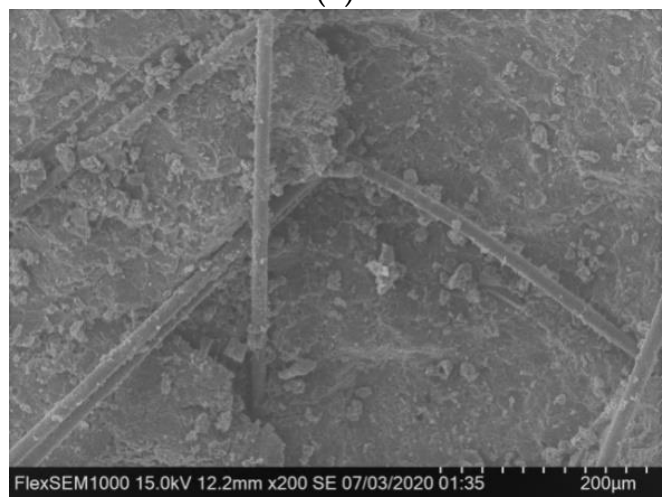

(c)

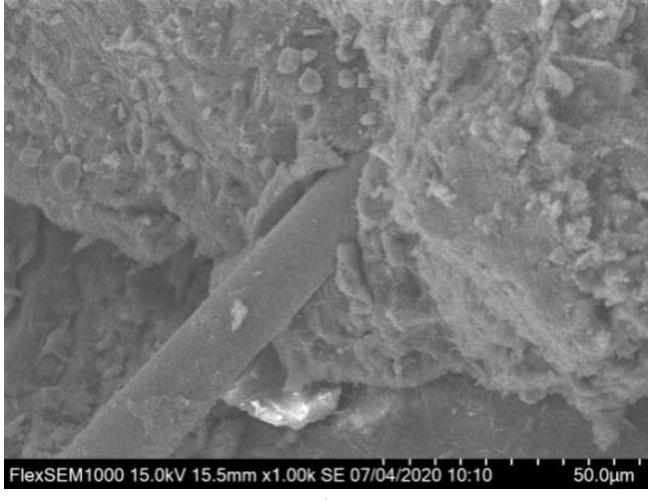

(b)

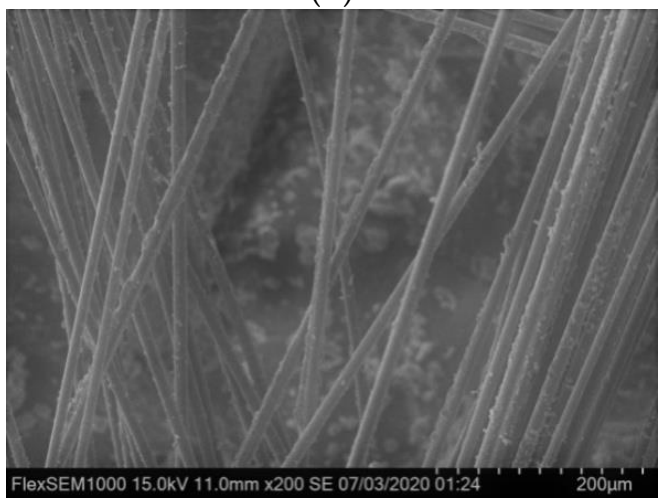

(d)

Figure 7. Microstructure of $28 \mathrm{~d}$ samples: $(\mathbf{a}, \mathbf{b})$ fiber and cement matrix bonding morphology, (c) fiber slip phenomenon, (d) fiber distribution structure characteristics in the matrix. 


\section{Conclusions}

In this experiment, the dynamic and static mechanical properties of SCM with five different alkali-resistant glass fiber contents (i.e., $0 \%, 0.25 \%, 0.5 \%, 0.75 \%, 1 \%$ ) were tested. Conclusions can be drawn as,

1. The incorporation of alkali-resistant glass fiber into SCM promoted the impact resistance of SCM. The static pressure resistance strength of SCM was found be proportional to the amount of alkali-resistant glass fiber.

2. The static pressure resistance strength of mortars had a negative relationship with fiber content when the fiber content exceeded $0.75 \%$, where G0.75 showed the best performance from the aspects of dynamic compressive strength and ultimate toughness in the strain rate range of $75.03 \mathrm{~s}^{-1} \sim 141.47 \mathrm{~s}^{-1}$. Furthermore, its DIF had a good representation as the range increases.

3. The bonding performance between alkali-resistant glass fiber and cement matrix was strong, and the fibers were interlaced in the mortar to form a network structure, which had a good effect on toughening and strengthening the SCM.

Author Contributions: Conceptualization, H.M. and Y.X.; methodology, L.W.; software, S.Y.; validation, H.M., S.Y. and L.W.; formal analysis, P.C.; investigation, S.Y.; resources, H.M.; data curation, S.Y.; writing—original draft preparation, H.M.; writing-review and editing, P.C.; visualization, S.Y.; supervision, Y.X.; project administration, H.M.; funding acquisition, H.M. All authors have read and agreed to the published version of the manuscript.

Funding: This work was supported by the Science and technology plan for housing and urban rural construction in Anhui Province (NO.2020-74).

Institutional Review Board Statement: Not applicable.

Informed Consent Statement: Not applicable.

Data Availability Statement: The data that support the findings of this study are available from the corresponding author upon reasonable request.

Acknowledgments: In the process of writing, this paper refers to many works, papers related to scientific and technological journals and relevant papers published on the Internet. The author would like to express his heartfelt thanks to the authors who have provided references and Enlightenment to the writing of this article. At the same time, we would like to express our sincere thanks to all editors and reviewers who have provided help and guidance for the writing of this article. Due to the large number of academic documents and online articles referred to, they will not be indicated one by one here. Please understand.

Conflicts of Interest: We declare that we do not have any commercial or associative interest that represents a conflict of interest in connection with the work submitted.

\section{References}

1. Liu, L.; Zhou, A.; Deng, Y.; Cui, Y. Strength performance of cement/slag-based stabilized soft clays. Constr. Build. Mater. 2019, 211, 909-918. [CrossRef]

2. Yuan, P.; Gong, L.M. Analysis of mechanics performance impact about fibrous material to gangue active powder concretes. Concrete 2009, 12, 58-60.

3. Fan, F.L.; Xu, J.Y.; Li, W.M.; Yang, J.Y.; Zhai, Y. Impact mechanical properties of slag-and fly ash-based geopolymer concrete. Explos. Shock. Waves 2009, 29, 516-522.

4. Xie, Y.L.; Zhao, L.; Zhang, Y. Research on the impact resistance properties of polyvinyl alcohol and polypropylene fiber concrete. Concrete 2017, 8, 70-73.

5. Rostami, R.; Zarrebini, M.; Mandegari, M.; Sanginabadi, K.; Mostofinejad, D.; Abtahi, S.M. The effect of concrete alkalinity on behavior of reinforcing polyester and polypropylene fibers with similar properties. Cem. Concr. Compos. 2018, 97, 118-124. [CrossRef]

6. Zhang, L.F.; Liang, Q.S.; Yin, Y.L. Research on the performance of polypropylene fiber reinforced alkali SCM. Concr. Cem. Prod. 2014, 11, 60-63.

7. Amer, I.; Kohail, M.; Elfeky, M.; Rashad, M. Evaluation of Using Cement in alkali-activated slag concrete. Int. J. Sci. Technol. Res. 2020, 9, 245. 
8. Maharishi, A.; Singh, S.P.; Gupta, L. Strength and durability studies on slag cement concrete made with copper slag as fine aggregates. Mater. Today 2020, 38, 15-25. [CrossRef]

9. Dong, Z.F. Research on Service Performance of Alkali-Resistant Cluster Glass Fiber Concrete and Polypropylene Geotextile Master's Thesis, Beijing University of Technology, Beijing, China, 2018.

10. Yue, L.F.; Li, D.X. Influences of Caustic-Resisting Glass Fiber to Mechanical Properties of Set Oil Well Cement Blended with Mineral Slag. Drill. Fluids Completion Fluids 2006, 23, 62-65.

11. Martin, T.; Taylor, S.; Robinson, D.; Cleland, D. Arching in concrete slabs strengthened with near surface mounted fiber reinforced polymers. Eng. Struct. 2019, 184, 257-277. [CrossRef]

12. Gao, N.; Yu, G.Q.; Zhao, Y.L.; Xue, Z.H.; He, W.M. Research on modified cement mortar mixed with glass fiber and polymer. Concr. Cem. Prod. 2016, 3, 53-57.

13. Wu, F.N. Research on Preparation of Alkali-Resistant Glass Fibers from Industrial Wastes Such as Blast Furnace Slag. Master's Thesis, University of Jinan, Jinan, China, 2016.

14. Dong, J.M.; Nie, H.; Yan, Y.J. Study on mechanical properties of sisal fiber reinforced self-compacting lightweight aggregate concrete. New Build. Mater. 2016, 8, 89-91.

15. Deng, Z.C.; Dong, Z.F. Impact Mechanical Properties of Fiber Reinforced Concrete Slab with Alkali-Resistant Glass Fiber of High Zirconium. J. Tianjin Univ. Nat. Sci. Eng. Technol. Ed. 2018, 51, 66-74. [CrossRef]

16. Chen, Y.Z.; Tian, C.J.; Chen, G.; Li, S.Z. Analysis of the inertial effect of the cylindrical specimen in SHPB system. Chin. J. Solid Mech. 2005, 1, 107-110.

17. ASTM C109, C109M-16a; Standard Test Method for Compressive Strength of Hydraulic Cement Mortars. ASTM International: West Conshohocken, PA, USA, 2016.

18. Yu, T.X.; Qiu, X.M. Impact Dynamics; Tsinghua University Press: Beijing, China, 2011; pp. 63-65.

19. Lu, M.; Xiao, H.; Liu, M.; Li, X.; Li, H.; Sun, L. Improved interfacial strength of $\mathrm{SiO}_{2}$ coated carbon fiber in cement matrix. Cem. Concr. Compos. 2018, 91, 21-28. [CrossRef]

20. Li, M.; Mao, X.B.; Cao, L.L.; Rong-Rong, M.A.; Hai, P.U. Experimental study on mechanical properties of coal under high strain rate. J. Min. Saf. Eng. 2015, 2, 317-324.

21. Gao, Q.; Wang, H.B.; Lv, N.; Zong, Q. Experimental study on mechanical characteristics of hard coal under different impact velocities. China Saf. Sci. Technol. 2019, 15, 69-74.

22. Deng, Z.C.; Xue, H.Q.; Zhang, P.F.; Li, P.Y.; She, X.J. Research on Flexural Impact Behavior of Alkali-Resistance Glass Fibers Reinforced Concrete. Highway 2007, 12, 184-187.

23. Yuan, S.J. Study on Collapse Failure Mechanism of Concrete Girder Bridge under Explosion Load. Ph.D. Thesis, Southeast University, Nanjing, China, 2019.

24. Sun, X.; Zhao, K.; Li, Y.; Huang, R.; Ye, Z.; Zhang, Y.; Ma, J. A study of strain-rate effect and fiber reinforcement effect on dynamic behavior of steel fiber-reinforced concrete. Constr. Build. Mater. 2018, 158, 657-669. [CrossRef]

25. Tian, Z.H.; Jiang, G.L.; Su, W.H.; Ni, J. Dynamic compressive properties of fiber mortar subjected to impact load. J. Vib. Shock. 2018, 37, 90-95.

26. Liang, N.H.; Yang, P.; Liu, X.R.; Zhang, Y.; Guo, Z.Q. A Study on Dynamic Compressive Mechanical Properties of Multi-Size Polypropylene Fiber Concrete Under High Strain Rate. Mater. Rev. 2018, 32, 288-294. 